www.jmscr.igmpublication.org Impact Factor 5.244

Index Copernicus Value: 83.27

ISSN (e)-2347-176x ISSN (p) 2455-0450

crossref DOI: _https://dx.doi.org/10.18535/jmscr/v4i10.57

\author{
Journal Of Medical Science And Clinical Research \\ IGM Publication \\ An Official Publication of IGM Publication
}

\title{
The Effect of Different Techniques of Microwave Disinfectionon Elastomeric Impression Materials (Laboratory and Microbiological Study)
}

\author{
Authors \\ Ahmed Abd El-Hamid', Enaya Shararah ${ }^{2}$, Dawlat Mostafa ${ }^{3}$, Shams Arafa ${ }^{4}$, \\ Eman Sabry 5 \\ ${ }^{1}$ Professor of Prosthodontics, Alexandria University Faculty of Dentistry, Alexandria, Egypt \\ ${ }^{2}$ Professor of Prosthodontics, Alexandria University Faculty of Dentistry, Alexandria, Egypt \\ ${ }^{3}$ Lecturer of Dental Biomaterials, Alexandria University Faculty of Dentistry, Alexandria, Egypt \\ ${ }^{4}$ Lecturer of Medical Microbiology and Immunology, Alexandria University Faculty of Medicine, Egypt \\ ${ }^{5}$ BDS, Faculty of Dentistry, Alexandria University, MS, Alexandria University, Egypt
}

\begin{abstract}
Dental impressions are often contaminated by exposure to saliva and blood. Microwave irradiation and immersion in solutions have been recommended for denture disinfection. However, the effect on impression materials has not been studied enough. Accordingly, the question is, is it possible to apply "Microwave disinfection" to impression materials vinyl siloxanether, polyvinyl siloxane and polyether? And if yes is it better to use with or without hydrogen peroxide $\left(\mathrm{H}_{2} \mathrm{O}_{2}\right)$ ? The Aim of this study is to evaluate and compare the effect of different techniques of microwave disinfection (microwave for 1 minute, 3 minutes and microwave with $\mathrm{H}_{2} \mathrm{O}_{2}$ for 1 minute and 3 minutes) on elastomeric impression materials (laboratory and microbiological study). Martials and methods: Specimens were made with vinyl siloxanether (Group I), polyvinyl siloxane (Group II) and polyether (Group III). Experimental groups were divided into Subgroup I :No disinfection measures (control group) , Subgroup II: The disinfection of samples were carried using microwave $630 \mathrm{w}$ immersed in saline for 1 minute, Subgroup III: The disinfection of samples were carried using microwave 630 $w$ immersed in saline for 3 minutes, Subgroup IV: The disinfection of samples were carried using microwave $630 \mathrm{w}$ immersed in hydrogen peroxide for 1 minute, Subgroup V:The disinfection of samples were carried using microwave $630 \mathrm{w}$ immersed in hydrogen peroxide for 3 minutes. The disinfection effect on bacteria and physical properties of impressions were evaluated. Result; Different techniques were significantly different $(P<.05)$ when compared with the control in reducing the number of colony forming units $(C F U)$ per unit volume $(\mathrm{mL})$ for both streptococcus mutans and candida albicans. The most significant reduction in the CFU/mL was noted when the disinfection of samples was carried using microwave $630 \mathrm{w}$ with hydrogen peroxide for 3minutes. No statistically significant difference was noted between the control and treatment groups in terms of all the physical properties tested (P>.05). Conclusion; Microwave disinfection decreased the CFU/ml of microorganisms in dental impressions, but it is more effective when samples immersed in hydrogen peroxide. Microwave disinfection with or without hydrogen peroxide had no effect on physical properties of polyvinyl siloxanether and polyvinyl siloxane but cause dimensional changes for polyether.

Keywords: microwave disinfection, elastomeric impression materials, hydrogen peroxide.
\end{abstract}




\section{Introduction}

Several items such as impressions, dental appliances and others are often heavily contaminated with microorganisms from saliva and blood. The risk of infections transmitted by saliva, blood and plaque is considered a potential occupational hazard as they contain pathogenic microorganisms and viruses which can transmit diseases from simple to highly virulent such as common cold, pneumonia, tuberculosis, viral hepatitis $\mathrm{B}$ and $\mathrm{C}$, herpes and acquired immunodeficiency syndrome. ${ }^{(1)}$

When considering methods and products for disinfection impressions, two factors are important: the antibacterial efficiency of disinfection procedures ${ }^{(2)}$ and the effect of these procedures on surface properties such as detail reproduction, surface roughness and wettability and dimensional alterations ${ }^{(3)}$

Chemical treatment (with, for example, glutaraldehyde, sodium hypochlorite, or povidone iodine) is the most commonly used method of disinfecting dental impressions. However, glutaraldehyde induces inhalation toxicity and eye irritation, sodium hypochlorite induces the bleaching of dental materials, and povidone iodine induces loss of pigmentation. ${ }^{(4,5)}$

Microwave ovens are simple to use, low in cost and can provide disinfection effect. (6) The disinfection of dentures with microwave irradiation has been attempted and has been found to be better than the use of sodium hypochlorite. (7)

Hydrogen peroxide $\left(\mathrm{H}_{2} \mathrm{O}_{2}\right)$ is commonly used disinfectant. Its effect caused by reactive oxygen molecules and such effect will therefore be enhanced if hydrogen peroxide is in the gaseous phase. It is found that, when microwave irradiation and certain concentrations of $\mathrm{H}_{2} \mathrm{O}_{2}$ were applied to sewage sludge at the same time, the formation of $\mathrm{OH}^{-}$caused by the microwave irradiation splitting the $\mathrm{H}_{2} \mathrm{O}_{2}$ confirmed that, this combination destroyed bacterial cell walls and therefore provided more effective disinfection. ${ }^{(8)}$
The present study is intended to compare the antimicrobial efficacy as well as the effect on dimensional accuracy and tear strength for polyvinyl siloxane, vinyl siloxanether and polyether impressions using microwave irradiation with and without hydrogen peroxide.

\section{Material and Method}

The present research includes two studies: microbiological study and laboratory study.

2.1. Microbiological study: An estimated sample size of 18 patients was selected, they were partially edentulous, weren't partially denture wearers. For each group, one type of impression material was used for 6 patients.

Group I: impressions were made from vinyl siloxanether (Identium ${ }^{\circledR}$ Medium, kettenbach $\mathrm{GmbH}$ )

Group II: impressions were made from polyvinyl siloxane (Elite® HD+ Regular Body, Zhermack).

GroupIII: impressions were made from polyether (Impregum ${ }^{\circledR}$ F, Handmix 3M ESPE Company). For each patient, 5 maxillary impressions were made to be divided into 5 subgroups

Subgroup I: No disinfection measures (Control group)

Subgroup II: The disinfection of samples was carried using microwave (DAEWOO, KOREA) 630w for 1 minute. (Samples were immersed in a beaker containing $40 \mathrm{ml}$ saline).

Subgroup III: The disinfection of samples which immersed in saline was carried using microwave for 3 minutes.

Subgroup IV: the disinfection was carried using microwave and hydrogen peroxide (Samples were immersed in a beaker containing $40 \mathrm{ml}$ of $3 \%$ $\mathrm{H}_{2} \mathrm{O}_{2}$ ) for 1 minute.

Subgroup V: The disinfection of samples which immersed in $\mathrm{H}_{2} \mathrm{O}_{2}$ was carried using microwave for 3 minutes.

After disinfection, each specimen was soaked in $40 \mathrm{ml}$ of sterile physiological saline.

In microbiological Lab, the following culture media were prepared:

1- MacConkey's agar plates. 
2- Sabouraud's dextrose agar plates.

The plates were incubated at $37^{\circ} \mathrm{C}$ aerobically. After incubation, the plates were examined for colonial growth. Microbial colonies were counted with the help of a magnifying glass. The count was then multiplied by reciprocal of the drop volume $(0.01 \mathrm{ml})$ to give the viable count which is the colony forming units per milliliter $(\mathrm{CFU} / \mathrm{ml})$. The colonies were picked up separately. A gram stained film was prepared for each colony and examined under light microscopic.

\subsection{Laboratory study}

\subsubsection{Dimensional stability test: Specimens} were prepared by a standardized die according to the ADA specification No. 19 for elastomeric impression materials. ${ }^{(9)}$ (fig.1) Measurements were made using a Tool Maker's measuring microscope (MSSI Company, West Germany). The distance between the cross lines cd \& c'd' on the test block was measured and recorded as reading $(L 1)$. The specimens were evaluated after disinfection recorded as reading (L2). According to ADA the percentage of linear dimensional change for each specimen:

$\Delta L=L 1-L 2 / L 1 \times 100$

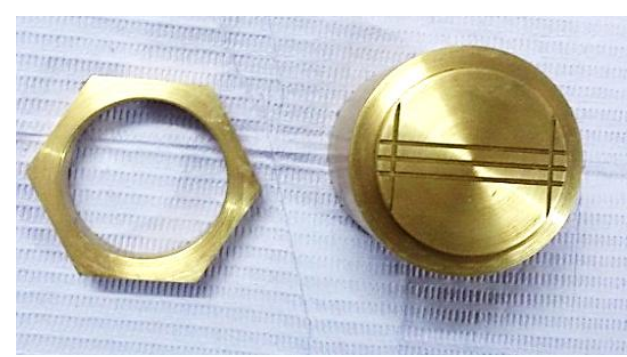

Fig. (1): A Metal die for making test specimens to evaluate dimensional changes.

2.2.2 Tear strength test: Specimens were made 90-degree angle - shaped free of nicks with a thickness of $1.8 \mathrm{~mm}$ according to the ASTM 1004 (10).After disinfection they were loaded in tension until failure at a rate of $51 \mathrm{~mm} / \mathrm{min}$ with a universal testing machine(USA Model No 942D 10-20) (fig.2).

The tear strength was calculated $T=F / D \quad N / m m$

Where: $T$ : is tear strength, $F$ : is the force required to cut the sample, D: is the thickness of the sample.

\section{Statistical Analysis}

The resulting data were fed to the computer and analyzed using IBM SPSS software package version 20.0. For normally distributed data, comparison between more than two populations was analyzed F-test (ANOVA) to be used and Post Hoc test (Scheffe). Correlations between two quantitative variables were assessed using Pearson coefficient. Qualitative data were described using number and percent. Comparison between different groups regarding categorical variables was tested using Chi-square test.

Tukey LSD. Significance test results were quoted as two-tailed probabilities. Significance of the obtained results was judged at the 5\% level. A pvalue of less than 0.05 was considered statistically significant.

\section{Results}

Percentages of decreasing of streptococcus mutans $(\mathrm{CFU} / \mathrm{ml})$ in different groups (different types of impressions) after disinfection with microwave for 1 min range from $-49.00 \%$ to $-52.36 \%$, microwave with $\mathrm{H}_{2} \mathrm{O}_{2}$ for 1 min range from $-73.31 \%$ to $75.38 \%$, microwave for 3 min range from- $91.12 \%$ to- $92.44 \%$ while after disinfection with microwave for 3 min with $\mathrm{H}_{2} \mathrm{O}_{2}$ reach $-100 \%$. (Graph.1) Percentages of decreasing of candida albicans $(\mathrm{CFU} / \mathrm{ml})$ in different groups after disinfection with microwave for $1 \mathrm{~min}$ range from $-38.33 \%$ to $-47.39 \%$, microwave with $\mathrm{H} 2 \mathrm{o} 2$ for 1 min range from $-45.50 \%$ to $-55.42 \%$, while after disinfection with microwave for $3 \mathrm{~min}$ with or without $\mathrm{H} 2 \mathrm{o} 2$ reach $-100 \%$.(Graph.2)

Linear dimensional changes in group I and group II after different disinfection techniques, were insignificantly different ( $p$ value $>0.05$ ) when comparing between the five subgroups, but in group III there were significant differences $(\mathrm{P}<.05)$. There were significant differences when comparing between three groups after disinfection 3 min with microwave with or without $\mathrm{H}_{2} \mathrm{O}_{2}$.

Tear strength, there was no statistically significant difference $(\mathrm{p}>>0.05)$ when comparing between 
three groups also when comparing between the five subgroups in each 3 groups.

Graph (1): Comparison between percentages (\%) of decreasing of streptococcus mutans from control in different impression specimens after different disinfection techniques.

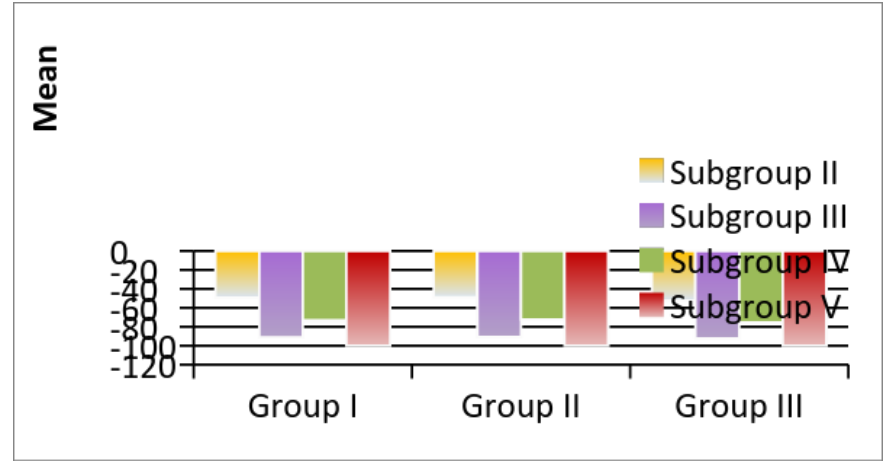

Graph (2): Comparison between percentages (\%) of decreasing of candida albicans from control in different impression specimens after different disinfection techniques.

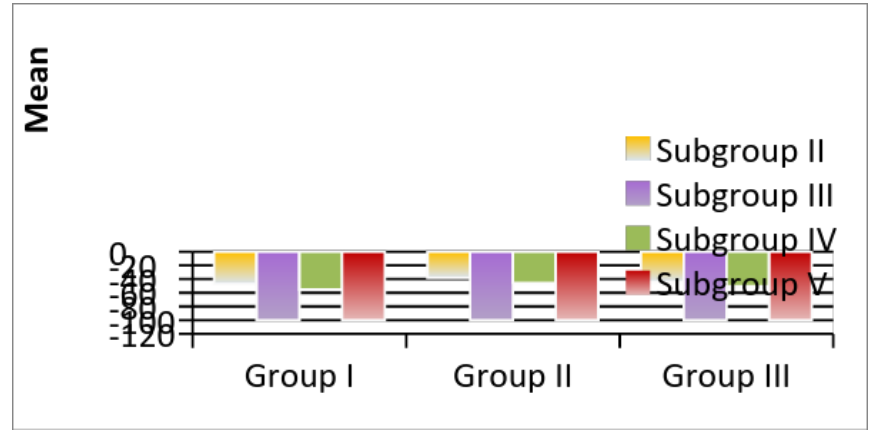

\section{Discussion}

Disinfection with microwave for 3 minutes resulted in survival of Streptococcus mutans after 24 incubation. Only the 3-minute specimens disinfected in microwave with $\mathrm{H}_{2} \mathrm{O}_{2}$ showed no CFU. The result obtained from present study was supported with vitro study of Choi et al. (2014) ${ }^{(11)}$ who evaluate the effectiveness of microwave irradiation and hydrogen peroxide against $S$ mutans and $\mathrm{E}$ coli for the polyvinyl siloxane impression materials. This because the formation of hydroxyl free radicals caused by the microwave irradiation splitting the $\mathrm{H}_{2} \mathrm{O}_{2}$, this combination destroyed bacterial cell walls and therefore provided more effective disinfection.

Disinfection with microwave for 3 minutes with or without $\mathrm{H}_{2} \mathrm{O}_{2}$ showed no CFU of Candida albicans. These results were in agreement with Campanha et al.(2013) ${ }^{(12)}$ they demonstrated that microwave irradiation inactivated $C$. albicans after 3 min.

Linear dimensional changes after disinfection for vinyl siloxanether and polyvinyl siloxane specimens were insignificantly different from control, but for polyether some linear dimensional changes occur. These results were in agreement with Thota et al. (2014) ${ }^{(13)}$, as polyether impression materials show same behavior when disinfected by autoclave because of their hydrophilic nature. So, following cold disinfection procedure is indicated for polyether.

The results of tear strength test showed that the three used impression materials after different disinfection techniques weren't significantly different from control specimens. The results were in agreement with Choi et al. (2014) ${ }^{(11)}$ who reported that microwave irradiation and hydrogen peroxide disinfection had no effect on tear strength of polyvinyl siloxane impression materials.

\section{Conclusion}

Microwave disinfection decreased the $\mathrm{CFU} / \mathrm{ml}$ of microorganisms in dental impressions, but it is more effective when samples immersed in hydrogen peroxide. Microwave disinfection with or without hydrogen peroxide had no effect on physical properties of polyvinyl siloxanether and polyvinyl siloxane but caused dimensional changes for polyether.

\section{References}

1. Emphasis PS. Infection control in dental office: a realistic approach. . J Am Dent Assoc, 112 ,pp. 458-68, 1986.

2. Egusa H, Watamoto T, Abe K, Kobayashi M, Kaneda Y, Ashida S, et al. An analysis of the persistent presence of opportunistic pathogens on patient-derived dental impressions and gypsum casts. The International journal of prosthodontics, 21, pp.62-8. 2008. 
3. Suprono MS, Kattadiyil MT, Goodacre CJ, Winer MS. Effect of disinfection on irreversible hydrocolloid and alternative impression materials and the resultant gypsum casts. The Journal of prosthetic dentistry,108, pp.250-8, 2012.

4. Moffa EB, Giampaolo ET, Izumida FE, Pavarina AC, Machado AL, Vergani CE. Colour stability of relined dentures after chemical disinfection. Arandomised clinical trial. J Dent, 39, pp.65-71, 2011.

5. Ballantyne B, Jordan SL. Toxicological, medical and industrial hygiene aspects of glutaraldehyde with particular reference to its biocidal use in cold sterilization procedures. Journal of applied toxicology : JAT, 21, pp.131-51,2001.

6. Silva MM, Vergani CE, Giampaolo ET, Neppelenbroek KH, Spolidorio DM, Machado AL. Effectiveness of microwave irradiation on the disinfection of complete dentures.The International journal of prosthodontics, 19, pp.288-93,2006.

7. Webb BC, Thomas CJ, Harty DW, Willcox MD. Effectiveness of two methods of denture sterilization. Journal of oral rehabilitation, 25, pp.416-23,1998.

8. Wong WT, Chan WI, Liao PH, Lo KV.A hydrogen peroxide/ microwave advanced oxidation process for sewage sludge treatment.Journal of environmental science and health Part A, Toxic/hazardous substances \& environmental engineering, 41 , pp.2623-33,2006.

9. American National Standards Institute/ American Dental Association. Specification No. 19: Dental elastometric impression materials. Chicago: American Dental Association. 2004.

10. American society for testing and Materials.ASTM Desigmation D 1004 Standard test methods for rubber materials - determination of tear strength - Annual book of ASTM standards. Section 8. Philadelphia: 1983.

11. Choi YR, Kim KN, Kim KM.The disinfection of impression materials by using microwave irradiation and hydrogen peroxide.The Journal of prosthetic dentistry, 112 , pp.981-7, 2014.

12. Campanha NH, Jorge JH, Giampaolo ET.Cell Membrane Integrity of Candida Albicans after Different Protocols of Microwave Irradiation. American Journal of Infectious Diseases and Microbiology, 1, pp. 38-45, 2013

13. Thota KK, Jasthi S, Ravuri R, S. T. A comparative evaluation of the dimensional stability of three different elastomeric impression materials after autoclaving An in vitro study. J Clin Diagn Res, 8 , pp.48-50, 2014. 